\title{
Transcatheter aortic valve implantation in patients with bicuspid aortic valve stenosis utilizing the next-generation fully retrievable and repositionable valve system: mid-term results from a prospective multicentre registry
}

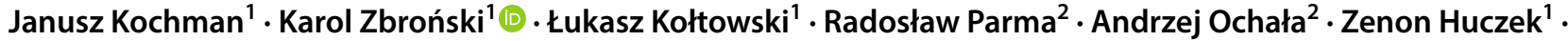 \\ Bartosz Rymuza ${ }^{1} \cdot$ Radosław Wilimski $^{5}$ - Maciej Dąbrowski ${ }^{3}$. Adam Witkowski ${ }^{3}$. Piotr Scisło ${ }^{1}$. Marek Grygier ${ }^{4}$. \\ Maciej Lesiak ${ }^{4}$ - Grzegorz Opolski ${ }^{1}$
}

Received: 20 February 2019 / Accepted: 22 August 2019 / Published online: 2 September 2019

(C) The Author(s) 2019

\begin{abstract}
Background The aim of this study was to evaluate the outcomes of transcatheter aortic valve implantation (TAVI) in bicuspid aortic valve (BiAV) stenosis using a mechanically expanded Lotus ${ }^{\mathrm{TM}}$ device. The prior experience with first-generation devices showed disappointing results mainly due to increased prevalence of aortic regurgitation (AR) that exceeded those observed in tricuspid stenosis.

Methods and results We collected baseline, in-hospital, 30-day and 2-year follow-up data from a prospective, multicentre registry of patients with BiAV undergoing TAVI using Lotus ${ }^{\mathrm{TM}}$ valve. Safety and efficacy endpoints were assessed according to VARC-2 criteria. The study group comprised 24 patients. The mean age was 73.5 years and the mean EuroSCORE 2 was $4.35 \pm 2.56 \%$. MDCT analysis revealed Type $1 \mathrm{BiAV}$ in $75 \%$ of patients. The mean gradient decreased from $60.1 \pm 18.3$ to $15 \pm 6.4 \mathrm{~mm} \mathrm{Hg}$, the AVA increased from $0.6 \pm 0.19$ to $1.7 \pm 0.21 \mathrm{~cm}^{2}$. One in-hospital death was observed secondary to aortic perforation. There was no severe AR and the rate of moderate AR equalled $9 \%$ at 30 days $(n=2)$. Device success was achieved in $83 \%$ and the 30-day safety endpoint was $17 \%$. In the 2-year follow-up, the overall mortality was $12.5 \%$ and the 2-year composite clinical efficacy endpoint was met in $25 \%$ of the patients $(n=6)$

Conclusions The TAVI in selected BiAV patients using the Lotus ${ }^{\mathrm{TM}}$ is feasible and characterized by encouraging valve performance and mid-term clinical outcomes.
\end{abstract}

Karol Zbroński

karol.zbronski@gmail.com

1 First Department of Cardiology, Medical University of Warsaw, ul. Banacha 1a, PL, 02-097 Warsaw, Poland

2 Medical University of Silesia, Katowice, Poland

3 Department of Interventional Cardiology and Angiology, Institute of Cardiology, Warsaw, Poland

4 Department of Cardiology, Poznan University of Medical Science, Poznan, Poland

5 Department of Cardiac Surgery, Medical University of Warsaw, Warsaw, Poland 


\section{Graphic abstract}
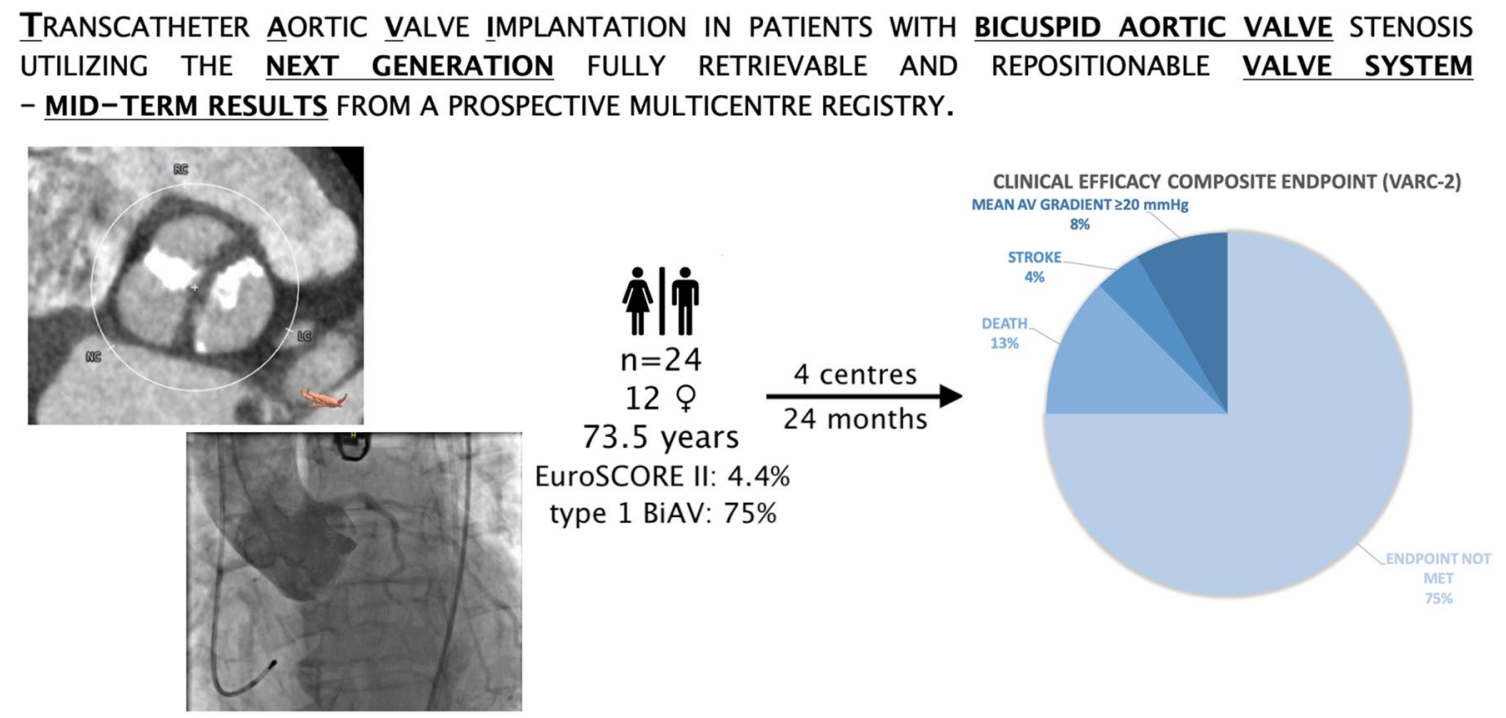

Keywords Transcatheter aortic valve implantation $\cdot$ Bicuspid aortic valve $\cdot$ Lotus ${ }^{\mathrm{TM}}$ valve

\section{Introduction}

A bicuspid aortic valve (BiAV) is the most common congenital heart defect reported in up to $2 \%$ of the general population $[1,2]$. The altered anatomy predisposes to a premature calcification and thickening of valve leaflets leading to development of aortic stenosis in large number of patients with BiAV [3]. Although the clinical symptoms occur earlier than in patients with tricuspid valve, BiAV is still an indication for aortic valve replacement (AVR) in significant number of elderly patients. In a recent study, $20 \%$ octogenarians who underwent surgical AVR had an underlying BiAV pathology [4]. As these individuals are characterized by an increased operative risk, they might also be suitable candidates for transcatheter aortic valve implantation (TAVI). Although TAVI is a well-established and recommended therapeutic option in high surgical-risk patients, it is still considered as a relative contraindication in BiAV anatomy [5, 6]. The current guidelines on the treatment of valvular disease have omitted this population from their recommendations, as the majority of landmark clinical trials excluded those with BiAV stenosis [7]. Unfavourable anatomy with heavily calcified and asymmetrical aortic valve cusps accompanied by annular eccentricity and aortopathy were perceived as features that could lead to prosthesis dysfunction and periprocedural complications. These concerns were further strengthened by results of few small TAVI registries that showed a higher rate of moderate-to-severe aortic regurgitation (AR) than in tricuspid valves [8-11]. The latter is probably associated with important drawbacks of the first-generation devices such as lack of dedicated sealing systems and limited ability to reposition the bioprosthesis. The new-generation Lotus ${ }^{\mathrm{TM}}$ Valve System (Boston Scientific, MA, USA) was designed to overcome the aforementioned restrictions. It adopts a unique mechanical expansion mechanism and is made of a singlebraided nitinol wire and three bovine pericardial leaflets. The device is fully repositionable and resheatable even in the expanded position, before final release. It is equipped with a surrounding flexible membrane designed to seal the paravalvular gaps between the prosthesis and native annulus, which aims to reduce the risk of significant paravalvular leaks (PVLs) [12-14]. This was confirmed in the REPRISE II trial in which the rate of moderate PVL was below $2 \%$ [15]. However, the data regarding Lotus performance in BiAV patients are scarce. To address this important clinical issue, we have performed safety and efficacy analysis of TAVI in patients with BiAV stenosis treated with Lotus ${ }^{\mathrm{TM}}$ valve implantation.

\section{Methodology}

The study was based on a prospective registry of patients with BiAV undergoing TAVI using Lotus ${ }^{\mathrm{TM}}$ valve in four academic centres in Poland. Patients entered into the registry were to meet the generally accepted criteria for TAVI, which included an intermediate or high surgical risk, endstage renal failure, chronic pulmonary disease, pulmonary hypertension or other contraindications to surgical aortic valve replacement (SAVR) not included in the risk scores 
(such as "porcelain" aorta, previous chest radiotherapy, previous pulmonary lobectomy, cirrhosis with portal hypertension, previous chest surgery, cognitive dysfunction due to neurological disease). Severe aortic stenosis was defined as an aortic valve area (AVA) $\leq 1 \mathrm{~cm}^{2}$ or indexed AVA $\leq 0.6$ $\mathrm{cm}^{2} / \mathrm{m}^{2}$, or mean aortic gradient $\geq 40 \mathrm{~mm} \mathrm{Hg}$ or an aortic velocity $\geq 4 \mathrm{~m} / \mathrm{s}$ in the presence of clinical symptoms. The database contains detailed demographic and clinical characteristics, results of imaging studies, including echocardiography and multi-detector computed tomography (MDCT), laboratory assessment, procedural outcomes and the results of a short-term and mid-term follow-up. The treating institutions followed patients prospectively using clinical and echocardiographic evaluations.

All patients included in the analysis underwent contrastenhanced, ECG-gated MDCT imaging using contemporary CT systems according to the local institutional CT scan protocols. The operators used the images for valve sizing and procedure planning. For the purpose of this analysis, the MDCT source data were collected and retrospectively re-evaluated by one experienced CT analyst using the 3Mensio valve analysis software (3Mensio Medical Imaging, Bithoven, The Netherlands). The annular plane was identified as the short axis through the nadir of each coronary cusps; and the diameter, perimeter and area were measured. Additional measurements were taken at the intercommissural distance $-4 \mathrm{~mm}$ above the annular plane, at the level of the ventricular outflow tract $(4 \mathrm{~mm}$ below the annular plane), sinus of Valsalva, and ascending aorta. The heights of both coronary ostia were also recorded. The eccentricity index of annular plane was calculated using the formula 1 - (minimal diameter/maximal diameter). Additionally, the degree of oversizing was derived from the annular plane perimeter (perimeter oversizing $=($ device perimeter - annular perimeter)/annular perimeter $\times 100)$ and annular plane area $($ area oversizing $=($ device area - annular area $) / a n n u-$ lar area $\times 100)$. BiAV morphology was described using the Sievers classification, which takes into account the number of cusps, the presence and spatial distribution of raphes [16]. The Type 0 was identified in the case of two fully developed cusps with one commissure and no raphe; Type 1 was characterized by one completely developed cusp and two smaller malformed cusps fused by one raphe; and Type 2 was assigned when two raphes were present. The functional BiAV was classified as a tricuspid valve with evident symmetry of all three cusps, secondarily fused by a degenerative process and no evidence of raphe. Further subcategories were reported according to the location of the raphe: $\mathrm{R}-\mathrm{L}$, $\mathrm{R}-\mathrm{N}, \mathrm{N}-\mathrm{L}$ (R: right, L: left, N: non-coronary). Based on the previous literature, any raphe below $3 \mathrm{~mm}$ long was considered as non-significant [4].

Pre-procedural, discharge, 30-day and 2-year echocardiographic results were entered by the participating centres and included the aortic annulus, aortic root and ascending aorta diameters, the aortic valve area, the peak/mean transvalvular gradient, the extent and distribution of valve calcifications, mitral and aortic valve regurgitation, mean transprosthetic gradient, and effective orifice area. AR after TAVI was defined as the sum of transvalvular and paravalvular regurgitation. Additionally, the paravalvular regurgitation was analysed separately. The AR was classified as none/trivial, mild, moderate or severe.

The technical aspects of TAVI have been described previously $[17,18]$. Briefly, all procedures were performed under general anesthesia or conscious sedation either in dedicated hybrid rooms or in cardiac catheterization laboratories. All patients underwent TAVI via the transfemoral approach; the vascular access was secured using either a Prostar 10 French XL (Abbott Vascular Device, Redwood City, California) or surgical technique, depending on the local protocols. A 20-French Lotus ${ }^{\mathrm{TM}}$ Introducer (Boston Scientific, MA, USA) was used for 23-mm Lotus ${ }^{\mathrm{TM}}$ valves and 22-French for those who received 25-mm and 27-mm valves. Balloon valvuloplasty with an undersized balloon was performed at the discretion of the operator. The positioning and deployment of Lotus ${ }^{\mathrm{TM}}$ valves strictly followed the manufacture's recommendations and were carried out based upon the best clinical practice $[13,15]$. A control angiography was done before final release of the valve to assess the appropriate positioning, the degree of AR and patency of coronary arteries. In case of suboptimal result, the valve was repositioned, and the aortography was repeated to ensure that no further manipulation was needed and to confirm a good final result.

The standard post-procedural care included observation at the intensive care unit for at least $24 \mathrm{~h}$ and duration was mainly related to post-procedural complications. A dual antiplatelet therapy was initiated in all patients comprising a life-long $75 \mathrm{mg}$ of acetylsalicylic acid and 3 months of $75 \mathrm{mg}$ of clopidogrel. In case of indications for oral anticoagulant, the decision regarding the choice of the molecule, dosage and duration was left to the decision of local heart team. Before discharge, all patients underwent transthoracic echocardiography. The patients were scheduled for a 30-day and a 24-month follow-up visits to collect clinical and echocardiographical data. The data were prospectively collected and entered into the registry.

The main endpoints of the study were device success and 30-day safety composite endpoint as defined by the VARC-2 criteria [19]. The secondary endpoint was 2-year all-cause mortality and 2-year composite clinical efficacy endpoint [as defined by the VARC-2 criteria). Device success comprised of the absence of procedural mortality, successful implantation of a single prosthesis with its appropriate placement and function (no severe prosthesis-patient mismatch $(<0.65$ $\mathrm{cm}^{2} / \mathrm{m}^{2}$ ), mean aortic valve gradient $<20 \mathrm{mmHg}$ or peak velocity $<3 \mathrm{~m} / \mathrm{s}$, no moderate/severe PVL] and successful 
retrieval of the delivery system. The 30-day safety composite endpoint included all-cause mortality, stroke/TIA, life-threatening bleeding, acute kidney injury (stage 2 or 3), coronary artery obstruction requiring intervention, major vascular complication and valve-related dysfunction requiring repeat procedure (BiAV, TAVI or SAVR). The 2-year clinical efficacy endpoint consisted of all-cause mortality, stroke, requiring hospitalizations for valve-related symptoms or worsening congestive heart failure, NYHA class III or IV and valve-related dysfunction.

Quantitative data are presented as mean and standard deviation (SD) or as median (interquartile range) and qualitative variables as numbers and percentages. An unpaired Student's $t$ test or Wilcoxon rank-sum test was used for comparison of quantitative variables, whereas the comparison of qualitative variables was performed with the two-tailed Fisher's exact test. Statistical significance was defined as $p<0.05$. Statistical analysis was performed using Medcalc ver.11 and Statistica ver. 12.

\section{Results}

Between March 2015 and December 2016, 24 patients met the inclusion criteria of the prospective registry and were included in the study. Baseline demographics and clinical characteristics are presented in Table 1. Briefly, the mean age was 75.3 years with equally distributed gender. Patients had moderate surgical risk and the majority of them demonstrated heart failure with NYHA III/IV symptoms. Detailed assessment of aortic stenosis severity and type of BiAV morphology are depicted in Table 2. The average mean gradient was $60.1 \pm 18.31 \mathrm{~mm} \mathrm{Hg}$, the mean AVA was $0.6 \pm 0.19 \mathrm{~cm}^{2}$. As far as the valve morphology is considered, Type 1 was the most frequently identified. Moderate/severe degree of valve calcification was recognized in majority of patients.

TAVI was performed via femoral route in all patients, in $46 \%$, the procedure was done with local anaesthesia and conscious sedation. Pre-implantation balloon valvuloplasty was conducted in majority of patients $(n=15,63 \%)$. The most frequently used valve was the Lotus ${ }^{\mathrm{TM}} 25 \mathrm{~mm}$. The repositioning/resheathing feature was used in $42 \%$ (ten patients) of the procedures, of which in two cases $(8.3 \%)$, complete prosthesis retrieval was required. The immediate angiographic assessment showed no severe AR (AR), in one case, a moderate AR was identified. The detailed procedural characteristics are depicted in Table 3.

The VARC-2-defined device success was achieved in $83 \%$ of patients $(n=20)$; the detailed breakdown of its composites is presented in Fig. 1.

There were no conversions to open-heart surgery. One patient required urgent abdominal surgery due to perforation of the tortuous abdominal aorta that was noted soon
Table 1 Baseline characteristics $(n=24)$

\begin{tabular}{ll}
\hline Age, years & $75.3 \pm 7.85$ \\
Female & $12(50)$ \\
Logistic Euroscore (\%) & $13.4 \pm 10.39$ \\
Euroscore 2 (\%) & $4.35 \pm 2.56$ \\
Height, cm & $162.5 \pm 6.83$ \\
BMI, kg/m ${ }^{2}$ & $28.0 \pm 4.65$ \\
NYHA functional class & \\
NYHA I & $3(13)$ \\
NYHA II & $6(25)$ \\
NYHA III or IV & $15(63)$ \\
Diabetes mellitus type 2 & $5(21)$ \\
Atrial fibrillation & $6(25)$ \\
Hypertension & $16(67)$ \\
Coronary artery disease & \\
None & $11(45)$ \\
CCS I or II & $13(55)$ \\
Previous myocardial infarction & $4(17)$ \\
Previous PCI & $1(4)$ \\
Previous CABG & $2(8)$ \\
Stroke/intracranial bleeding & $3(13)$ \\
Previous pacemaker & $4(17)$ \\
Peripheral artery disease & $4(17)$ \\
COPD & $7(29)$ \\
Pulmonary hypertension & $2(8)$ \\
eGFR, mL/min & $64.4 \pm 16.51$ \\
\hline
\end{tabular}

Values are mean $\pm \mathrm{SD}$ or $n(\%)$

$C C S$ Canadian cardiology scale, $C A B G$ coronary artery bypass grafting, $C O P D$ chronic obstructive pulmonary disease, $e G F R$ estimated glomerular filtration rate, $M I$ myocardial infarction, $N Y H A$ New York Heart Association

after insertion of the Lotus introducer sheath, which was complicated by cardiogenic shock and multi-organ failure resulting in death on day 7 .

Any type of VARC-2 bleeding and vascular complications occurred in 29.2\% $(n=7)$ and $25 \%(n=6)$, respectively. Life-threatening and major bleedings occurred in three patients (13\%) and all were directly related to the procedure. There were two overt access site bleedings, and one caused by the above-mentioned abdominal aorta perforation. Major vascular complications were found in three subjects. Of which, two haematomas and one aforementioned aortic perforation were diagnosed and required blood transfusion of at least four units.

There was one minor stroke diagnosed 1 day after the procedure with full recovery within next $72 \mathrm{~h}$ (due to limited availability and lack of reimbursement, cerebral protection was not implemented in any of the procedures). The pre-discharge echocardiographic assessment showed significant reduction of the mean gradient from $60.1 \pm 18.3$ to $15 \pm 6.4 \mathrm{~mm} \mathrm{Hg}$ and increase in the AVA 
Table 2 Pre-procedural echocardiographic and computed tomographic imaging assessment $(n=24)$

Transthoracic echocardiography

AVA $\mathrm{cm}^{2}$

$0.6 \pm 0.19$

AVA indexed, $\mathrm{cm}^{2} / \mathrm{m}^{2}$

Maximum velocity, $\mathrm{m} / \mathrm{s}$

Mean gradient, $\mathrm{mm} \mathrm{Hg}$

Ejection fraction, \%

$\leq 30 \%$

Pulmonary artery pressure, $\mathrm{mm} \mathrm{Hg}$

Mitral regurgitation

$\begin{array}{ll}\text { None/trivial } & 2(8) \\ \text { Mild } & 15(63) \\ \text { Moderate } & 7(29) \\ \text { Severe } & 0(0)\end{array}$

Tricuspid regurgitation

None/trivial

$3(13)$

Mild

Moderate

Severe

Aortic regurgitation

None/trivial

$9(38)$

Mild

$11(46)$

Moderate

3 (13)

Severe

Multi-detector computed tomography

Annular plane

Minimal diameter, $\mathrm{mm}$

Maximal diameter, $\mathrm{mm}$

Eccentricity index

Perimeter, $\mathrm{mm}$

Area, $\mathrm{cm}^{2}$

Area-derived diameter, $\mathrm{mm}$

Perimeter-derived diameter, $\mathrm{mm}$

Intercommissural distance $4 \mathrm{~mm}$ above the plane, $\mathrm{mm}$

Left ventricular outflow tract

Minimal diameter, $\mathrm{mm}$

Maximal diameter, $\mathrm{mm}$

Eccentricity index

Perimeter, $\mathrm{mm}$

Area, $\mathrm{cm}^{2}$

Area-derived diameter, $\mathrm{mm}$

Perimeter-derived diameter, $\mathrm{mm}$

Calcium scoring, $\mathrm{mm}^{3}$

Distance of annulus to ostia of coronary arteries, $\mathrm{mm}$

Left ostium

Right ostium

Diameter of the ascending aorta

Bicuspid valve types

Type 0

Type 1

Left-right

$22 \pm 2.9$

$28 \pm 3.0$

$0.21 \pm 0,92$

$77 \pm 4.8$

$0.5 \pm 0.06$

$25 \pm 2.6$

$26 \pm 2.6$

$25 \pm 3.9$

$22 \pm 3,5$

$30 \pm 3.4$

$0.28 \pm 0.125$

$84 \pm 9.7$

$0,5 \pm 1.24$

$25 \pm 3.0$

$27 \pm 3,1$

$1779 \pm 819.1$

$14 \pm 3.2$

$16 \pm 2.5$

$38 \pm 4.6$

2 (8)

$18(75)$

$15(63)$
Table 2 (continued)

\begin{tabular}{ll}
\hline Right-noncoronary & $2(8)$ \\
Left-noncoronary & $1(4)$ \\
Type 2 & $0(0)$ \\
Functional & $2(8)$ \\
Undetermined & $2(8)$ \\
\hline
\end{tabular}

Values are mean $\pm \mathrm{SD}$, mean $\pm \mathrm{SD}$ (minimum, maximum) or $\mathrm{n}(\%)$

Eccentricity index was determined using the formula: 1 - (minimal diameter/maximal diameter)

Perimeter oversizing was determined using the formula [(device perimeter - annular perimeter)/annular perimeter $\times 100$ ]

Area oversizing was determined using the formula [(device area annular area)/annular area $\times 100]$

Table 3 Procedural characteristics $(n=23)$

Lotus valve size

$\begin{array}{ll}23 \mathrm{~mm} & 8(35) \\ 25 \mathrm{~mm} & 10(43) \\ 27 \mathrm{~mm} & 5(22) \\ \text { Balloon predilatation } & 15(65) \\ \text { Aortic regurgitation by angiography } & \\ \text { None/trivial } & 15(65) \\ \text { Mild } & 7(30) \\ \text { Moderate } & 1(4) \\ \text { Severe } & 0(0) \\ \text { Device oversizing, \% } & \\ \text { Perimeter } & -2.9 \pm 7.13 \\ \text { Area } & -1.3 \pm 14.46 \\ \text { Contrast media, mL } & 132 \pm 64.2 \\ \text { Duration of procedure, min } & 139 \pm 79.0 \\ \text { Fluoroscopy duration, min } & 35 \pm 15.1 \\ \text { Radiation dose, mGy } & 1587 \pm 1098.7\end{array}$

Percentage calculated for 23 patients, as in 1 patient, the valve was not implanted due to abdominal aorta perforation and need for urgent abdominal surgery

from $0.6 \pm 0.19$ to $1.7 \pm 0.21 \mathrm{~cm}^{2}$. There was no severe AR; in two patients (9\%), a moderate regurgitation was found (Table 4).

The 30-day safety composite end point was achieved in $17 \%(n=4)$; a detailed breakdown of the composites is presented in Table 5 . There were neither any post-discharge deaths, episodes of new bleeding nor vascular complications. Seven patients (35\%) required new pacemaker implantation for advanced conduction disturbances.

In the 2-year follow-up, additional two deaths were reported resulting in overall mortality of $12.5 \%$. The 2 -year composite clinical efficacy endpoint was met in $25 \%$ of the patients $(n=6)$ (Table 6$)$. 
Fig. 1 Device success and composites of Lotus valve implantation. Primary outcome measure of Valve Academic Research Consortium 2-defined device success and its composites. $A R$ aortic regurgitation

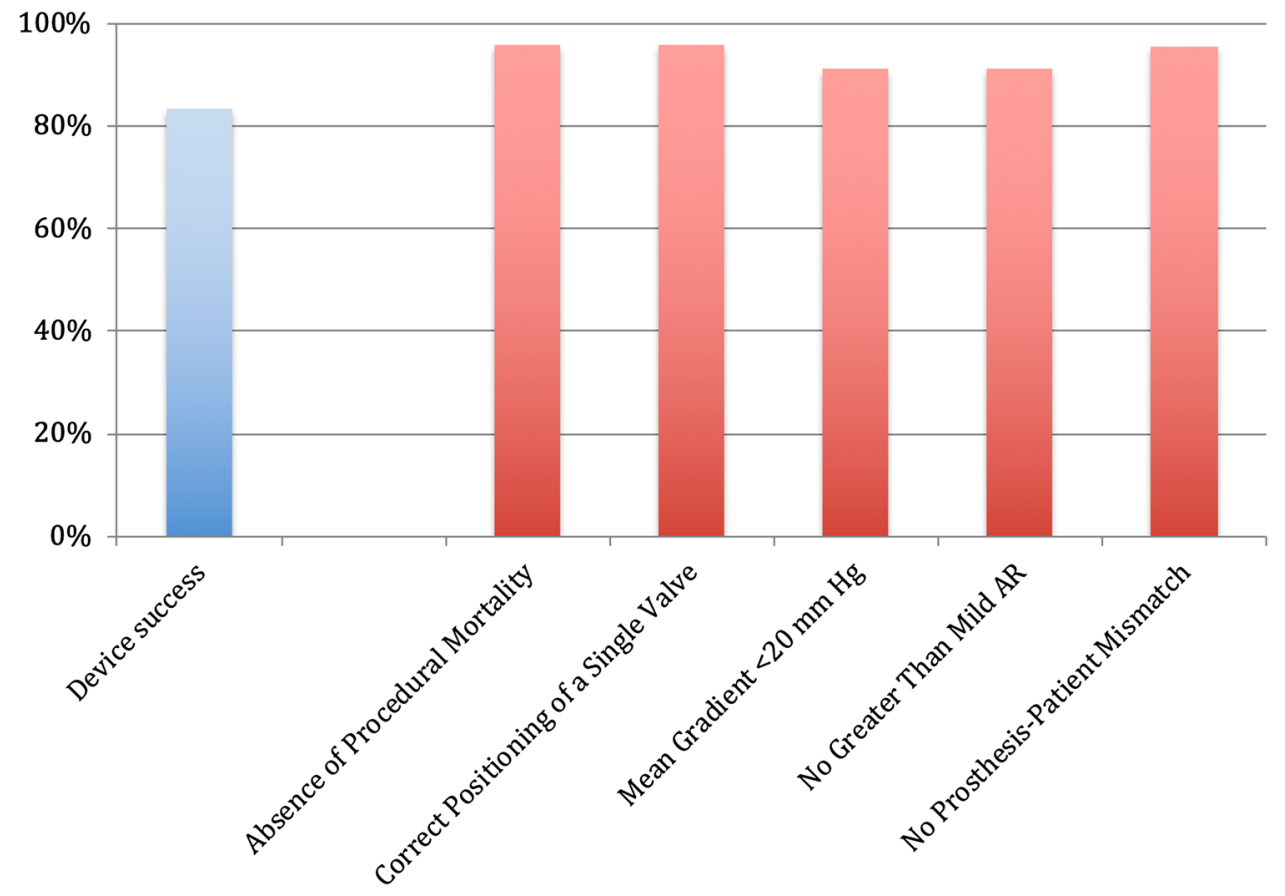

\section{Discussion}

To the best of our knowledge, this is the first study presenting 2-year outcomes of TAVI in a consecutive multicentre series of patients with bicuspid aortic valve stenosis treated with new-generation Lotus ${ }^{\mathrm{TM}}$ valve. The system was first certified and introduced in March 2015; however, due to technical difficulties with the locking mechanism, it has been temporarily withdrawn from the market and the second reiteration (Lotus Edge ${ }^{\mathrm{TM}}$ ) was introduced in December 2018. However, despite using the previous version, we have demonstrated that implantation of this bioprosthesis in a challenging $\mathrm{BiAV}$ anatomy is safe and feasible resulting in favorable valve performance and low incidence of significant PVLs. The latter finding is of particular interest as prior experience with first-generation valves revealed high risk of AR in patients with BiAV stenosis [10, 20, 21]. In the recent multicentre, patient-level meta-analysis comprising 108 patients, the rate of moderate and severe AR was 30.8\% at 30 days [20]. Similar frequency of significant AR (32\%) in BiAV patients treated with first-generation devices was previously reported by our group [10]. These outcomes may raise some concerns, as there is clear evidence that significant AR is associated with an increased late mortality [6, 22]. In the present study, there was no severe AR, whereas moderate was found in only two patients $(8 \%)$. There is number of factors that could potentially explain these favorable outcomes, among which the inherent properties of the Lotus $^{\mathrm{TM}}$ device seem to play an important role. The ability to resheath and reposition the bioprosthesis at any stage of the deployment process, which was utilized in nearly half of our patients, facilitates accurate and precise positioning, and allows for final assessment of the fully functional state before disconnecting the delivery system. Moreover, implantation does not require rapid pacing assuring haemodynamic stability throughout the procedure. Additionally, the adaptive seal may reduce degree of PVLs by filling the gaps between the prosthesis and the native valve. This recently published REPRISE II study confirmed the low risk of post-implantation AR in tricuspid aortic valve anatomy [15]. Although the results are promising, it remains unknown whether the decreased rates of moderate and severe ARs observed with the Lotus ${ }^{\mathrm{TM}}$ device will have an impact on the long-term mortality of patients with BiAV stenosis.

The sizing of the bioprosthesis based on MDCT that was utilized in all our patients is another important factor proved to have a positive impact on the rate of device success. As shown in the largest published registry on TAVI in BiAV, the utilization of MDCT resulted in more than 50\% reduction of significant post-procedural ARs [8]. Additionally, the diagnostic value of this imaging technique in comparison with echocardiography has a higher sensitivity and specificity for identification of BiAV, especially in Type 1 , in which raphe could be overshadowed by calcifications [23].

The detailed analysis of procedural data revealed some degree of device undersizing, which causes are not fully understood. Traditionally profound undersizing was considered to be associated with higher incidence of AR and device embolization, therefore, was contraindicated. This recommendation was based on experience from tricuspid anatomy patients and thus not necessarily applicable to patients with different anatomy. In fact, in our cohort, the degree of AR 
Table 4 Procedural and in-hospital clinical outcomes

\begin{tabular}{|c|c|}
\hline \multicolumn{2}{|l|}{ Procedural and clinical outcomes $(n=24)$} \\
\hline Conversion to cardiothoracic surgery & $0(0)$ \\
\hline Valve migration & $0(0)$ \\
\hline Coronary obstruction & $0(0)$ \\
\hline Cardiac tamponade & $0(0)$ \\
\hline \multicolumn{2}{|l|}{ Bleeding } \\
\hline Life-threatening/disabling & $1(4)$ \\
\hline Major & $2(8)$ \\
\hline \multicolumn{2}{|l|}{ Minor } \\
\hline Blood transfer ( $\geq 4$ units) & $3(13)$ \\
\hline MI & $1(4)$ \\
\hline Stroke/TIA/RIND & $1(4)$ \\
\hline \multicolumn{2}{|l|}{ Vascular complications } \\
\hline Major & $3(13)$ \\
\hline Minor & $3(13)$ \\
\hline Acute kidney injury & $1(4)$ \\
\hline Permanent pacemaker implantation & $6\left(30^{\mathrm{a}}\right)$ \\
\hline Successful valve implantation & $23(96)$ \\
\hline Hospital stay, days & $10 \pm 5.3$ \\
\hline \multicolumn{2}{|l|}{ Echocardiographic outcomes $\left(n=23^{\mathrm{b}}\right)$} \\
\hline Ejection fraction, $\%$ & $51 \pm 11.2$ \\
\hline AVA, $\mathrm{cm}^{2}$ & $1.7 \pm 0.21$ \\
\hline AVA indexed, $\mathrm{cm}^{2} / \mathrm{m}^{2}$ & $0.85 \pm 0.175$ \\
\hline Mean gradient, $\mathrm{mm} \mathrm{Hg}$ & $15 \pm 6.4$ \\
\hline Maximal velocity, $\mathrm{m} / \mathrm{s}$ & $2.7 \pm 0.64$ \\
\hline \multicolumn{2}{|l|}{ Aortic regurgitation } \\
\hline None/trivial & $16(70)$ \\
\hline Mild & $5(22)$ \\
\hline Moderate & $2(9)$ \\
\hline Severe & $0(0)$ \\
\hline $\begin{array}{l}\text { Paraprosthetic aortic regurgitation } \\
\text { None/trivial } \\
\text { Mild } \\
\text { Moderate } \\
\text { Severe }\end{array}$ & $\begin{array}{l}17(74) \\
4(17) \\
2(9) \\
0(0)\end{array}$ \\
\hline $\begin{array}{l}\text { Mitral regurgitation } \\
\text { None/trivial } \\
\text { Mild } \\
\text { Moderate } \\
\text { Severe }\end{array}$ & $\begin{array}{l}6(26) \\
14(61) \\
3(13) \\
0(0)\end{array}$ \\
\hline Pulmonary artery pressure, $\mathrm{mm} \mathrm{Hg}$ & $43 \pm 15.9$ \\
\hline
\end{tabular}

${ }^{\text {a }}$ Percentage calculated for 20 patients, as 4 patient had previous pacemaker

${ }^{b}$ Percentage calculated for 23 patients, as 1 patient did not undergo valve implantation due to abdominal aorta perforation and need for urgent abdominal surgery

was low despite an evident undersizing. One may speculate that a more aggressive approach and implantation of larger valves would have resulted in even lower risk of post-procedural AR, as it has been shown that oversizing can minimize the risk of significant AR [24]. On the other hand, excessive oversizing may cause aortic root rupture/haematoma [25],
Table 5 30-day clinical and echocardiographic outcomes

\begin{tabular}{|c|c|}
\hline \multicolumn{2}{|l|}{ Clinical outcomes $(n=24)$} \\
\hline All-cause mortality & $1(4)$ \\
\hline Stroke disabling and non-disabling & $1(4)$ \\
\hline MI & $0(0)$ \\
\hline \multicolumn{2}{|l|}{ Bleeding complications } \\
\hline Life-threatening/disabling & $1(4)$ \\
\hline Major & $2(8)$ \\
\hline Minor & $4(17)$ \\
\hline \multicolumn{2}{|l|}{ Vascular complications } \\
\hline Major & $3(13)$ \\
\hline Minor & $3(13)$ \\
\hline Acute kidney injury & $1(4)$ \\
\hline Permanent pacemaker implantation & $7\left(35^{\mathrm{a}}\right)$ \\
\hline \multicolumn{2}{|l|}{ Echocardiographic outcomes $\left(n=23^{\mathrm{b}}\right)$} \\
\hline Ejection fraction, $\%$ & $53 \pm 12.5$ \\
\hline Aortic valve area, $\mathrm{cm}^{2}$ & $1.7 \pm 0.16$ \\
\hline Mean gradient, $\mathrm{mm} \mathrm{Hg}$ & $14 \pm 4.3$ \\
\hline Maximum velocity, $\mathrm{m} / \mathrm{s}$ & $2.3 \pm 0.44$ \\
\hline \multicolumn{2}{|l|}{ Aortic regurgitation } \\
\hline None/trivial & $16(70)$ \\
\hline Mild & $5(22)$ \\
\hline Moderate & $2(9)$ \\
\hline Severe & $0(0)$ \\
\hline \multicolumn{2}{|l|}{ Paraprosthetic aortic regurgitation } \\
\hline None/trivial & $17(74)$ \\
\hline Mild & $4(17)$ \\
\hline Moderate & $2(9)$ \\
\hline Severe & $0(0)$ \\
\hline \multicolumn{2}{|l|}{ Mitral regurgitation } \\
\hline None/trivial & $6(26)$ \\
\hline Mild & $14(61)$ \\
\hline Moderate & $3(13)$ \\
\hline Severe & $0(0)$ \\
\hline Pulmonary artery pressure, $\mathrm{mm} \mathrm{Hg}$ & $45 \pm 16.9$ \\
\hline
\end{tabular}

${ }^{a}$ Percentage calculated for 20 patients, as 4 patient had previous pacemaker

${ }^{\mathrm{b}}$ Values calculated for 23 patients as 1 patient died

coronary obstruction [26], or atrioventricular block [27, 28]. Additionally, the specific BiAV anatomy characterized by high leaflet coaptiation, extensive asymmetric calcifications and ellipticity of the annulus can lead to incomplete and asymmetric valve expansion, which may impact the acute valve performance and its long-term durability. Therefore, it has been suggested that valve sizing in bileaflet anatomy might require different sizing approach than that currently used in tricuspid valves. Namely, it should not be based solely on the annular but rather on supra-annular measurements taking into account the intracommissural distance. The observed device undersizing in our registry suggests that operators applied this new strategy [29]. 
Table 6 Two-year clinical and echocardiographic outcomes

\begin{tabular}{|c|c|}
\hline \multicolumn{2}{|l|}{ Clinical outcomes $(n=24)$} \\
\hline All-cause mortality & $3(12.5)$ \\
\hline Clinical efficacy according to VARC-2 & $6(25)$ \\
\hline Stroke disabling and non-disabling & $1(4.2)$ \\
\hline MI & $0(0)$ \\
\hline \multicolumn{2}{|l|}{ Bleeding complications } \\
\hline Life-threatening/disabling & $1(4.2)$ \\
\hline Major & $2(8.3)$ \\
\hline Minor & $4(16.6)$ \\
\hline \multicolumn{2}{|l|}{ Vascular complications } \\
\hline Major & $3(12.5)$ \\
\hline Minor & $3(12.5)$ \\
\hline Acute kidney injury & $1(4.2)$ \\
\hline Permanent pacemaker implantation & $7\left(35^{\mathrm{a}}\right)$ \\
\hline \multicolumn{2}{|l|}{ Echocardiographic outcomes $\left(n=21^{\mathrm{b}}\right)$} \\
\hline AVA, $\mathrm{cm}^{2}$ & $2.0 \pm 0.5$ \\
\hline AVA indexed, $\mathrm{cm}^{2} / \mathrm{m}^{2}$ & $1.2 \pm 0.3$ \\
\hline Maximum velocity, $\mathrm{m} / \mathrm{s}$ & $2.6 \pm 0.5$ \\
\hline Mean gradient, $\mathrm{mm} \mathrm{Hg}$ & $15.8 \pm 10$ \\
\hline Ejection fraction, $\%$ & $51.9 \pm 11$ \\
\hline$\leq 30 \%$ & $0(0)$ \\
\hline \multicolumn{2}{|l|}{ Mitral regurgitation } \\
\hline None/trivial & $16(76.2)$ \\
\hline Mild & $4(19)$ \\
\hline Moderate & $1(4.8)$ \\
\hline Severe & $0(0)$ \\
\hline \multicolumn{2}{|l|}{ Tricuspid regurgitation } \\
\hline None/trivial & $18(85.7)$ \\
\hline Mild & $2(9.5)$ \\
\hline Moderate & $1(4.8)$ \\
\hline Severe & $0(0)$ \\
\hline \multicolumn{2}{|l|}{ Aortic regurgitation } \\
\hline None/trivial & $20(95)$ \\
\hline Mild & $1(4.8)$ \\
\hline Moderate & $0(0)$ \\
\hline Severe & $0(0)$ \\
\hline
\end{tabular}

${ }^{\text {a}}$ Percentage calculated for 20 patients, as 4 patient had previous pacemaker

${ }^{\mathrm{b}}$ Values calculated for 21 patients as 3 patients have died

It should also be taken into account that the new-generation valves are equipped with sealing cuff that could further overcome the previously observed drawbacks of undersizing. The recently published data regarding the newgeneration balloon-expandable Sapien 3 valve in patients with large annuli exceeding the indicated dimensions, confirmed excellent results with no moderate or severe AR despite the inevitable undersizing [30]. These results were further supported by another analysis of Sapien 3, which showed that a low degree of MDCT area oversizing $(<5 \%)$ is associated with decreased rates of AR [28]. To validate this hypothesis-generating findings, a dedicated study with new-generation devices and a revised annulus-sizing algorithm would be needed.

The presented device success in our cohort was relatively high (83\%), despite the adverse anatomic characteristics typical for bicuspid patients and was comparable to that reported in tricuspid valves. It should be noticed that in our study, the VARC-2 criteria were utilized, whereas most of the published outcomes are based on the first definition of VARC, which does not take into account the prosthesis-patient mismatch. The recent publication with Lotus ${ }^{\mathrm{TM}}$ valve in tricuspid aortic stenosis showed $84 \%$ device success based on VARC-2 criteria [31]. We did not observe any valve embolization, coronary obstruction or need for surgical aortic valve replacement, and the 30-day composite safety end point was similar to that observed in tricuspid valve populations [32]. Of note, despite the use of larger sheath sizes, the rates of bleedings as well as vascular complications were not significantly higher as compared to outcomes from other new-generation devices. This can partially be explained by appropriate patient selection, especially with respect to the femoral artery size. It should be noted that the 30 -day mortality was $4 \%$, which seems relatively high taking into account the moderate risk profile of our cohort, but results from a relatively substantial impact of the one death on the overall mortality. Furthermore, in the 2-year follow-up, the all-cause mortality was $12.5 \%$, which is well within the published literature [21]. New pacemaker implantation was performed in seven patients (35\%), which is in the range of the prior results of TAVI in BiAV utilizing first-generation devices (14-50\%) and is similar to the rate observed in tricuspid valves treated with the Lotus ${ }^{\mathrm{TM}}$ prosthesis $(29 \%)[8-11,10,11]$. The freedom from the clinical efficacy composite endpoint after 2 years was observed in $75 \%$ of the study population-a result which is difficult to compare with the previously published reports, due to the scarcity of a long-term follow-up based on VARC-2 criteria in this cohort of patients in the currently available literature. In the already-mentioned study by Yousef et al. after 1 year of follow-up, the all-cause mortality was $16.9 \%, 4.3 \%$ of patients remained heavily symptomatic (NYHA class III-IV) and $27.7 \%$ had AR $\geq 2+[20]$. In one of the largest analyses of new-generation valves in BiAV [21], which included 11 patients treated with Lotus ${ }^{\mathrm{TM}}$ device, 30-day mortality in that subpopulation was $9.1 \%$, while the early safety endpoint was met in $18.2 \%$ (due to one death and one major vascular complication). No significant differences in VARC-2-defined endpoints at 30 days between the Lotus ${ }^{\mathrm{TM}}$ valve and the remaining prostheses were observed. Overall, new-generation devices were associated with less paravalvular regurgitation. Of note, all-cause mortality of the entire group was $14.4 \%$ at 1 year, which is in line with our findings. In another recently published study-RESPOND—31 
patients with BiAV had undergone Lotus ${ }^{\mathrm{TM}}$ valve implantation. One death and one stroke were observed in 30-day follow-up. There were no cases of moderate or severe PVL and the pacemaker rate was $22.2 \%$ [33]. Again, the mid-term mortality ( $9.7 \%$ at 1 year) was in agreement with our results.

\section{Study limitations}

The main limitation of our study is the lack of randomization with all inherent restrictions of this type of study design. Second, we couldn't exclude a bias related to relative weight of each centre that may limit the generalizability of outcomes. Third, the echocardiographic findings, especially the post-procedural AR, were not assessed by an independent core laboratory, which might have impacted the reported outcomes, as these parameters are operator dependent. Fourth, the differentiation between functional and congenital bicuspid valves is difficult, therefore, we cannot exclude some degree of misclassification in this respect. Fifth, as the registry includes only patients who underwent TAVI procedure, this could have potentially lead to a selection bias and thus the presented results should be interpreted with caution.

\section{Conclusions}

In conclusion, the TAVI in selected BiAV patients using the Lotus ${ }^{\mathrm{TM}}$ is feasible and characterized by encouraging valve performance and clinical outcomes. It should be noted that the presented cohort was of a moderate surgical risk as described by the low EuroSCORE 2, therefore, these findings should be viewed with caution when discussing high-risk patients. Although the overall number of analysed subjects is low, the study sample should not be regarded as negligible especially in view of the inadequate body of evidence currently available in the literature.

\section{Impact on daily practice}

We have shown that implantation of the second generation, repositionable and retrievable, transcatheter valve system in bicuspid aortic valve anatomy is safe and efficient in selected patients; these results may impact the current contraindications for TAVI.

Acknowledgements The authors would like to thank Professor Jean Claude Laborde for his expert advice during the procedures.

\section{Compliance with ethical standards}

Conflict of interest Janusz Kochman-travel grants from Medtronic, Boston Scientific, Abbott-speaker and proctor; Zenon Huczekproctor for Abbott and Medtronic; Lukasz Koltowski-travel grants from Medtronic, Boston Scientific, Edwards; Marek Grygier-Boston
Scientific — speaker, proctor and advisory board member, Medtronicspeaker and proctor; Maciej Lesiak-advising and speaker honoraria, Boston Scientific; Other authors do not declare any conflict of interest.

Open Access This article is distributed under the terms of the Creative Commons Attribution 4.0 International License (http://creativeco mmons.org/licenses/by/4.0/), which permits unrestricted use, distribution, and reproduction in any medium, provided you give appropriate credit to the original author(s) and the source, provide a link to the Creative Commons license, and indicate if changes were made.

\section{References}

1. Siu SC, Silversides CK (2010) Bicuspid aortic valve disease. J Am Coll Cardiol 55:2789-2800

2. Nistri S, Basso C, Marzari C, Mormino P, Thiene G (2005) Frequency of bicuspid aortic valve in young male conscripts by echocardiogram. Am J Cardiol 96:718-721

3. Reardon MJ, Adams DH, Kleiman NS, Yakubov SJ, Coselli JS, Deeb GM, Gleason TG, Lee JS, Hermiller JB, Chetcuti S, Heiser J, Merhi W, Zorn GL, Tadros P, Robinson N, Petrossian G, Hughes GC, Harrison JK, Maini B, Mumtaz M, Conte JV, Resar JR, Aharonian V, Pfeffer T, Oh JK, Qiao H, Popma JJ (2015) 2-year outcomes in patients undergoing surgical or self-expanding transcatheter aortic valve replacement. J Am Coll Cardiol 66:113-121

4. Roberts WC, Ko JM (2005) Frequency by decades of unicuspid, bicuspid, and tricuspid aortic valves in adults having isolated aortic valve replacement for aortic stenosis, with or without associated aortic regurgitation. Circulation 111:920-925

5. Leon MB, Smith CR, Mack M, Miller DC, Moses JW, Svensson LG, Tuzcu EM, Webb JG, Fontana GP, Makkar RR, Brown DL, Block PC, Guyton RA, Pichard AD, Bavaria JE, Herrmann HC, Douglas PS, Petersen JL, Akin JJ, Anderson WN, Wang D, Pocock S, Trial Investigators PARTNER (2010) Transcatheter aortic-valve implantation for aortic stenosis in patients who cannot undergo surgery. N Engl J Med 363:1597-1607

6. Smith CR, Leon MB, Mack MJ, Miller DC, Moses JW, Svensson LG, Tuzcu EM, Webb JG, Fontana GP, Makkar RR, Williams M, Dewey T, Kapadia S, Babaliaros V, Thourani VH, Corso P, Pichard AD, Bavaria JE, Herrmann HC, Akin JJ, Anderson WN, Wang D, Pocock SJ, Trial Investigators PARTNER (2011) Transcatheter versus surgical aortic-valve replacement in high-risk patients. $\mathrm{N}$ Engl J Med 364:2187-2198

7. Nishimura RA, Otto CM, Bonow RO, Carabello BA, Erwin JP, Guyton RA, O'Gara PT, Ruiz CE, Skubas NJ, Sorajja P, Sundt TM, Thomas JD, ACC, AHA Task Force Members (2014) 2014 AHA/ACC Guideline for the Management of Patients With Valvular Heart Disease: executive summary: a report of the American College of Cardiology/American Heart Association Task Force on Practice Guidelines. Am Heart Assoc J 129:2440-2492

8. Mylotte D, Lefèvre T, Søndergaard L, Watanabe Y, Modine T, Dvir D, Bosmans J, Tchétché D, Kornowski R, Sinning J-M, Thériault-Lauzier P, O'Sullivan CJ, Barbanti M, Debry N, Buithieu J, Codner P, Dorfmeister M, Martucci G, Nickenig G, Wenaweser P, Tamburino C, Grube E, Webb JG, Windecker S, Lange R, Piazza N (2014) Transcatheter aortic valve replacement in bicuspid aortic valve disease. J Am Coll Cardiol 64:2330-2339

9. Hayashida K, Bouvier E, Lefèvre T, Chevalier B, Hovasse T, Romano M, Garot P, Watanabe Y, Farge A, Donzeau-Gouge P, Cormier B, Morice M-C (2013) Transcatheter aortic valve implantation for patients with severe bicuspid aortic valve stenosis. Circ Cardiovasc Interv 6:284-291 
10. Kochman J, Huczek Z, Ścisło P, Dabrowski M, Chmielak Z, Szymański P, Witkowski A, Parma R, Ochala A, Chodór P, Wilczek K, Reczuch KW, Kubler P, Rymuza B, Kołtowski Ł, Ścibisz A, Wilimski R, Grube E, Opolski G (2014) Comparison of one and 12-month outcomes of transcatheter aortic valve replacement in patients with severely stenotic bicuspid versus tricuspid aortic valves (Results from a Multicentre Registry). Am J Cardiol 114(5):757-762

11. Bauer T, Linke A, Sievert H, Kahlert P, Hambrecht R, Nickenig G, Hauptmann KE, Sack S, Gerckens U, Schneider S, Zeymer U, Zahn R (2014) Comparison of the effectiveness of transcatheter aortic valve implantation in patients with stenotic bicuspid versus tricuspid aortic valves (from the German TAVI Registry). Am J Cardiol 113:518-521

12. Gooley R, Lockwood S, Antonis P, Meredith IT (2013) The SADRA Lotus Valve System: a fully repositionable, retrievable prosthesis. Miner Cardioangiol 61:45-52

13. Meredith IT, Hood KL, Haratani N, Allocco DJ, Dawkins KD (2012) Boston scientific lotus valve. EuroIntervention 8(Suppl Q):Q70-Q74

14. Grygier M, Araszkiewicz A, Lesiak M, Oko-Sarnowska Z, Trojnarska O, Olasińska-Wiśniewska A, Misterski M, Buczkowski P, Jemielity M, Grajek S (2015) The new generation is coming. Percutaneous implantation of the fully repositionable Lotus $₫$ aortic valve prosthesis: the first Polish experience. Kardiol Pol 73:80-84

15. Meredith Am IT, Walters DL, Dumonteil N, Worthley SG, Tchétché D, Manoharan G, Blackman DJ, Rioufol G, Hildick-Smith D, Whitbourn RJ, Lefèvre T, Lange R, Müller R, Redwood S, Allocco DJ, Dawkins KD (2014) Transcatheter aortic valve replacement for severe symptomatic aortic stenosis using a repositionable valve system: 30-day primary endpoint results from the REPRISE II study. J Am Coll Cardiol 64:1339-1348

16. Sievers H-H, Schmidtke C (2007) A classification system for the bicuspid aortic valve from 304 surgical specimens. J Thorac Cardiovasc Surg 133:1226-1233

17. Grube E, Schuler G, Buellesfeld L, Gerckens U, Linke A, Wenaweser P, Sauren B, Mohr F-W, Walther T, Zickmann B, Iversen S, Felderhoff T, Cartier R, Bonan R (2007) Percutaneous aortic valve replacement for severe aortic stenosis in highrisk patients using the second- and current third-generation self-expanding CoreValve prosthesis: device success and 30-day clinical outcome. J Am Coll Cardiol 50:69-76

18. Webb JG, Chandavimol M, Thompson CR, Ricci DR, Carere RG, Munt BI, Buller CE, Pasupati S, Lichtenstein S (2006) Percutaneous aortic valve implantation retrograde from the femoral artery. Circulation 113:842-850

19. Kappetein AP, Head SJ, Généreux P, Piazza N, van Mieghem NM, Blackstone EH, Brott TG, Cohen DJ, Cutlip DE, van Es G-A, Hahn RT, Kirtane AJ, Krucoff MW, Kodali S, Mack MJ, Mehran R, Rodés-Cabau J, Vranckx P, Webb JG, Windecker S, Serruys PW, Leon MB (2012) Updated standardized endpoint definitions for transcatheter aortic valve implantation: the valve academic research consortium-2 consensus document. J Am Coll Cardiol 60:1438-1454

20. Yousef A, Simard T, Webb J, Rodés-Cabau J, Costopoulos C, Kochman J, Hernández-Garcia JM, Chiam PT, Welsh RC, Wijeysundera HC, García E, Ribeiro HB, Latib A, Huczek Z, Shanks M, Testa L, Farkouh ME, Dvir D, Velianou JL, Lam BK, Pourdjabbar A, Glover C, Hibbert B, Labinaz M (2015) Transcatheter aortic valve implantation in patients with bicuspid aortic valve: A patient level multi-center analysis. Int J Cardiol 189:282-288

21. Yoon SH, Lefèvre T, Ahn JM, Perlman GY, Dvir D, Latib A, Barbanti M, Deuschl F, De Backer O, Blanke P, Modine T, Pache G, Neumann FJ, Ruile P, Arai T, Ohno Y, Kaneko H, Tay E, Schofer N, Holy EW, Luk NHV, Yong G, Lu Q, Kong WKF, Hon J, Kao HL, Lee M, Yin WH, Park DW, Kang SJ, Lee SW, Kim YH,
Lee CW, Park SW, Kim HS, Butter C, Khalique OK, Schaefer U, Nietlispach F, Kodali SK, Leon MB, Ye J, Chevalier B, Leipsic J, Delgado V, Bax JJ, Tamburino C, Colombo A, Søndergaard L, Webb JG, Park SJ (2016) Transcatheter Aortic Valve Replacement With Early- and New-Generation Devices in Bicuspid Aortic Valve Stenosis. J Am Coll Cardiol 68(11):1195-1205

22. Adams DH, Popma JJ, Reardon MJ, Yakubov SJ, Coselli JS, Deeb GM, Gleason TG, Buchbinder M, Hermiller J, Kleiman NS, Chetcuti S, Heiser J, Merhi W, Zorn G, Tadros P, Robinson N, Petrossian G, Hughes GC, Harrison JK, Conte J, Maini B, Mumtaz M, Chenoweth S, Oh JK (2014) Transcatheter aorticvalve replacement with a self-expanding prosthesis. N Engl J Med 370:1790-1798

23. Tanaka R, Yoshioka K, Niinuma H, Ohsawa S, Okabayashi H, Ehara S (2010) Diagnostic value of cardiac CT in the evaluation of bicuspid aortic stenosis: comparison with echocardiography and operative findings. AJR Am J Roentgenol 195:895-899

24. Leber AW, Eichinger W, Rieber J, Lieber M, Schleger S, Ebersberger U, Deichstetter M, Vogel J, Helmberger T, Antoni D, Riess G, Hoffmann E, Kasel AM (2013) MSCT guided sizing of the Edwards Sapien XT TAVI device: impact of different degrees of oversizing on clinical outcome. Int J Cardiol 168:2658-2664

25. Barbanti M, Yang T-H, Rodés-Cabau J, Tamburino C, Wood DA, Jilaihawi H, Blanke P, Makkar RR, Latib A, Colombo A, Tarantini G, Raju R, Binder RK, Nguyen G, Freeman M, Ribeiro HB, Kapadia S, Min J, Feuchtner G, Gurtvich R, Alqoofi F, Pelletier M, Ussia GP, Napodano M, de Brito FS, Kodali S, Nørgaard BL, Hansson NC, Pache G, Canovas SJ, Zhang H, Leon MB, Webb JG, Leipsic J (2013) Anatomical and procedural features associated with aortic root rupture during balloon-expandable transcatheter aortic valve replacement. Circulation 128:244-253

26. Gurvitch R, Tay EL, Wijesinghe N, Ye J, Nietlispach F, Wood DA, Lichtenstein S, Cheung A, Webb JG (2011) Transcatheter aortic valve implantation: lessons from the learning curve of the first 270 high-risk patients. Catheter Cardiovasc Interv 78:977-984

27. Schroeter T, Linke A, Haensig M, Merk DR, Borger MA, Mohr FW, Schuler G (2012) Predictors of permanent pacemaker implantation after Medtronic CoreValve bioprosthesis implantation. Europace 14:1759-1763

28. Yang T-H, Webb JG, Blanke P, Dvir D, Hansson NC, Nørgaard BL, Thompson CR, Thomas M, Wendler O, Vahanian A, Himbert D, Kodali SK, Hahn RT, Thourani VH, Schymik G, Precious B, Berger A, Wood DA, Pibarot P, Rodés-Cabau J, Jaber WA, Leon MB, Walther T, Leipsic J (2015) Incidence and severity of paravalvular aortic regurgitation with multidetector computed tomography nominal area oversizing or undersizing after transcatheter heart valve replacement with the sapien 3: a comparison with the sapien XT. JACC Cardiovasc Interv 8:462-471

29. Kochman J, Rymuza B, Huczek Z (2015) Transcatheter aortic valve replacement in bicuspid aortic valve disease. Curr Opin Cardiol 30(6):594-602

30. Schaefer A, Linder M, Treede H, Deuschl F, Schofer N, Seiffert M, Schneeberger Y, Blankenberg S, Reichenspurner H, Schaefer U, Conradi L (2016) Applicability of next generation balloonexpandable transcatheter heart valves in aortic annuli exceeding formally approved dimensions. Clin Res Cardiol 105:585-591

31. Gooley RP, Talman AH, Cameron JD, Lockwood SM, Meredith IT (2015) Comparison of self-expanding and mechanically expanded transcatheter aortic valve prostheses. JACC Cardiovasc Interv 8:962-971

32. Bagur R, Kwok CS, Nombela-Franco L, Ludman PF, de Belder MA, Sponga S, Gunning M, Nolan J, Diamantouros P, Teefy PJ, Kiaii B, Chu MWA, Mamas MA (2016) Transcatheter aortic valve implantation with or without preimplantation balloon aortic valvuloplasty: a systematic review and meta-analysis. J Am Heart Assoc 5:e003191 
33. Blackman DJ, Van Gils L, Bleiziffer S, Gerckens U, Petronio AS, Abdel-Wahab M, Werner N, Khogali SS, Wenaweser P, Wöhrle J, Soliman O, Laborde JC, Allocco DJ, Meredith IT, Falk V, Van
Mieghem NM (2019) Clinical outcomes of the lotus valve in patients with bicuspid aortic valve stenosis: an analysis from the RESPOND study. Catheter Cardiovasc Interv 93(6):1116-1123 